\title{
The Time of Ascension / Convergence. The Great Claim - Universe Pattern: Equality in Non-Existence, Freedom in Existence": The New Free Human Realm of Existence, Miraculous Time of Freedom
}

\author{
Asistant Prof. Dr. Imran Gür, \\ Modern Turkish Literature \\ Email: iletisim@imrangur.com
}

Doi:10.5901/mjss.2014.v5n23p2444

\begin{abstract}
The tree-time occurring through the process during which humanity gets stuck into one of the three diverse cycles is regarded as the single response given to " a single question" by those it created within the "historical time" which comprises the duration when it manifested itself on earth through having been created alone, apart from the three distinct cycles. The topmost perception of time consisting of a fraction of "the historical time" with its incorporeal/spiritual realm, which is the time of existence suggests that it has been the incorrect answer to the problem of existence within a single-choice universe since the beginning of the existence of humanity. The "new realm of existence" of humanity which itself is the trinity of "the creator- the creation- the created" and which is created for the purpose of being free as a complete realm of existence through the coincidence/overlap of the three diverse cycles on a single point is the name of the "miraculous time" that manifests itself by the ability to identify a free individual who is created through the process when those three cycles coincided. The miraculous time is the alternative time of existence in which man's problem of the Creator, creation and being created is redefined. This is the miraculous time which integrates the Creator's act of creation and time, human being's state of having been created, his/her time as the created being and the act of creation of both parties within the "creation "time / cycle itself; that which is based on the principle of "equality in non-existence, freedom in existence" and which expresses the beginning/origin of the " major claim universe pattern/model" in the history of the Creator and humanity. It is the time of freedom in which the potential and the realm of existence of humanity through which man passes from childhood he/she never experienced before to the period of adulthood can be redefined.
\end{abstract}

Keywords: Three principles, essences, the descending, the fall, ascension, the miraculous time.

1. The Principal of Creation: The Act of Creation As the Major Claim of the Creator, The Major Claim-Universe Pattern': Equality in Non-Existence, Freedom in Existence: Creation As the Fulfillment/Wholeness of Descending and Ascending

Starting from the beginning of the history of humanity until today, the problem of creating that exists on the focal point of the fact that man cannot be identified as a completely "free" realm of existence, "is that man is identified as the production- creating out of the created over a created-creation dilemma which takes form with the relationship and communication between the history of humanity man him/herself created and the "other created realms of existence" and on the upper limit of which a "created" universe exists." (Kant, 1993: 39) The definitions for the human being and time based on the spatial existence which is the existence of the single-choice pattern/model of universe have been established on the "man's nature which gains existence/the quality of being in the existing created time. The problem of creating that already places itself in the position of the motive for being human and puts man in the position of the fundamental characteristic that allows him/her to be identified as at least heterogenous rather than heteronomous is seen to have been trapped within the created-creation-created loop. Accordingly, "man exists within the single perception of two different realms, the former of which is the created time that surpasses (beyond) man - the incorporeal time - and the latter of which is the historical time man him/herself created; while the problem of creating exists in the position of the process which takes shape with the relationship between the historical time and the being/entity who/which himself/itself has also been created, and with the communication man establishes with them."(Nietzche, 2009: 45) At the heart of the dual definitions of existence lies the problem that man who him/herself is also a created entity is unable to work out the relationship among him/herself, creation and tha state of being created. The most important reason for this situation is that man has tried to resolve the creation problem from the basis of the state of creating - having been created and by way of his/her relationship and communication with the created, and he has, in the method of resolution, based the 
relationship between "creation" and metaphysics on the time of existence - duration - which itself is also a created time. Therefore, "the act of creating is built upon the created-created dilemma of ephemeral (mortal) man who himself/herself is also a created being and the one without a chance to create existence out of nothingness and vice versa, and on the upper limit of "creating /creation" lies the relationship that man establishes with the time of existence - the metaphysics." (Heidegger, 1996: 72) "The most fundamental problem, on the other hand, is the fact that the time of existence which exists within the field of metaphysics where man's act of creating takes place is recognized not as a created time but as a creative time within creation." (Derrida 1982: 48)

Whereas, man's problem of "creating" is the state of "having been the Creator- creation - the created", which can only be worked out within a triplet/trio system/constitution(trinity), and the "act of creating" is a " thing in itself" in which this trinity/trio structure will get resolved. What puts human creations in the position of production/reproduction is the man's state of being a creature that cannot create a being/existence out of nothing but that can create existence out of existence or nothing and nihility out of existence. Accordingly, man, just as he cannot create existence out of nothing, he also does not have the capability of annihilating the existence/beings. On the other hand, he/she also does not stand a chance of determining or choosing his/her birth and death as a being existing within the overall duration of the created time and being born and passing away on earth within this period of time. Such a circumstance created a "single-choice universe pattern" where man's own being (him/herself ) got stuck or trapped within the incorporeal and biological times of the initial circumstances of his/her being, thus, man, in this sense, is the being who got stuck in the problem of creation and the realm of perception taking shape with the communication he/she established with the created beings. (Heidegger, 2001: 17) The problem of "creating/creation" is, in effect, the "thing in itself" as the problem-solutionreason/motive which man can work out together with the Creator, and the solution/resolution' of the problem is the motive/reason itself for the creation of man. Man, on the other hand, is the "thing in itself " who is created to work out this problem as "three in a row- totality" in "the act of creating". In this sense, man is an "incomplete being" existing as the potential of working out the " single-choice universe pattern" and the "creation" problem on earth that is the realm of spatial existence. However, to date, as an "incomplete being", he/she has been the one who has fulfilled the problem of "creation" by uniting with the created beings, and who, therefore, could not put into practice as the "thing in itself" the purpose of creation, the products of which were the Word and the "pattern of universe", and in which being human has become the problem of being unable to become human". - justification of animal- (Derrida, 2008: 12) Accordingly, the problem of creation is the matter of working out "the purpose of creation" that can be resolved with the trio of "Creator creation-the created".

None of the circumstances in which man, who himself is also the created one, fails to work out the creation problem with the Creator allows man to fulfill himself as the complete circle of existence, nor do they allow that which is created as the free act of creation to settle in the position of a total/complete realm of existence in which reality is not a word/speech or a fiction but the tangible reality itself. According to this, man is the being created to establish a direct communication with the Creator. The reason/motive for his being in the position of an " incomplete (half ) circle of existence" in the spatial realm is the purpose itself in his/her becoming a complete being by fulfilling his/her incomplete existence with the Creator. "One of the two options/choices - which is the only choice humanity has been in until today - is the option of spatial existence where man has defined him/herself with the other created ones." (Gür, 2012/2: 108) The second option, on the other hand, is the direct communication itself which means getting fulfilled/completed with the Creator, as in the descending of the revelation bearing the same meaning with purpose of creation and creation of man. Direct communication, as well as being the "creation" itself, is also the time of creation of the "durational existence" which brings the Creator and the created being, man, close together in "creation", and which bears the quality of totality of the spatial existence. "In this sense, the being/existence of man within the "spatial existence" is his/her potential of getting fulfilled with the "durational existence" through the direct communication." (Gür, 2013: 47) The fulfillment /completion of man (who is the fulfilled "potential of existence" in the durational existence ) by the Creator from " his/her own potential" means being re-created from outside the created duration/time and from the potential of creation not yet performed by the Creator. Whereas, humanity has settled in the position of the realm of existence which fulfilled its own being/existence with the other created ones right from the start of the time when it began to appear on earth until the last moment and which consumed its potential of creation as an incomplete being along with the other created ones that existed and in communication with those created in the created time. "Consuming, in the spatial existence, the destination of which ends up in nihility and nothingness, is the most prominent characteristic of man in that spatial existence where those produced by human hand use up his/her own very being in order to bring nothingness and absence, hence, to "create" not an existence out of existence but nothing and absence out of existence." (Gür, 2014/1: 28)

Such a condition which is the reason why humanity cannot exist as humans in their own potential existence deprives man of the superiority to become a free being who gets to know his/her Creator, allow his/her existence together 
with the "Creator" and utilize the potential of his/her creation in accordance with the purpose of creation, in other words, man lacks the ability to attain the quality of becoming human. For this reason, the attempts of man to resolve his incorporeal and biological existence/being have comdemned him/her to a nonexistence /nothingness that his/her own potential of being/existence turns itself into nothing in the "wrong option" by taking him not to the moment and the beginning of creation that is the beginning of his/her own cause or qualities of existence but, on the contrary, back to the overall total duration of the created time, which is the "created duration". For the same reason, man cannot be in a time of existence other than the created one, and the time of creation coincides with (overlaps) the created time of existence, and the overlapping/coinciding time destroys man's potential of being/existence.

As a result, not only is man unable to become a being that creates realm of existence from the act of "creation" itself which exists in man's own potential of being, but he/she is also deprived of the opportunity to converge with the very being of the Creator and communicate with the "Creator". In this sense, the sole objective of the "creative potential" of man, which is his/her basic attribute, and which distinguishes him/her from the other realms of existence is to resolve the "creation" problem consisting of the trinity/trio of "Creator-creation-the created", which exist in man for this purpose. Man himself/herself created as the purpose of the Creation alone is the question the Creator raised towards him (man); the universe of the created is one of the options placed in front of man to answer that question; and the Creator's act of creating and "Himself/thing in itself" (the Creator Himself) , on the other hand, ranks in the second option (that which has not yet been chosen, the Alternative). Man's chance to exist in the second option is possible through his/her ability to converge /unite with the Creator in creation as a created being, however, this will only be possible when the communication takes place not together with the other "created beings", but with the "Creator Himself/ thing in itself".

Accordingly, the Creator brought man into existence merely a potential of "thing in itself" in order to "be able to solve out the problem of creation"; yet, humanity's problem of creation so far today, including himself as a created being, has been the experience of working it out in" the relationships with the created beings", which turns out to have been the only option. Man, within the single-choice spatial existence where s/he is in communication/contact with the created ones and fulfills his/her being and existence through the relationships with them, exists as a "speech-based" organic system, for whom "the sound-realm of existence-things s/he produces are "words(utterances/articulation/speech)" out of the potential of creation." (Gür, 2013: 19) On the other hand, in the event that there is a communication taking place through the convergence between man and the "Creator" in the purpose of the creation, what is "created" is not the "word/speech" but the process of man's gaining his/her own Identity/Essence as the "thing in itself". Inasmuch as man, who exists within the trinity of "the Creator-the created-created", carries out the communication with the Creator, he himself/herself becomes the "thing in itself" created by the Creator in the "vertical center of existence". This is the state in which man witnesses/ testifies his/her own creation while s/he is becoming a "thing in itself" and fulfills her/his own being lessence and existence not with those created, but in unison with the Creator in creation itself.

Act of Creating is established on three fundamental bases. The first is the fact that the Creator's "act of creation" is a " major claim". This claim is the potency /power to transfer the state of being from nothingness - the negative (passive) - into an existence (positive/active), the faculty that cannot be found in the created beings, since nothing created has the competence to "create" an existence / a being from nothingness. In this sense, the sole unrivalled and unique Creator (sui generis) beyond comparison is that which, in His act of "creating" brings the being into existence by taking it from the negative (- minus) and bringing it forth to the positive (+plus), continuing the act of "creation" by creating existence from an existence. Existing in the position of the "major claim- universe pattern", man is the addressee (respondent) of this "creation" activity. This is the state in which man is to work out the act of "creating" as a response to the question addressed to him/her by the Creator". In this context, it is the specific question addressed to man himself/herself (in propria persona) and also the overall universal question addressed to the whole humanity existing as the addressee/respondent of the universe.

Nevertheless, while the overall/general question expresses the fact that all creation apart from man him/herself is the " big question" confronted by man, the specific question is the "haecceity lindividuality" of a single human being existing as " a mortal being on earth" that is within his own essence, specific to him/her and related with his/her own life. Haecceity lindividuality is the life of man himself/herself that the Creator created specifically and personally for the individual, which separates man's essential realm from his functional realm and makes him/her the center of "thing in itself " in creation, in which case it is the assurance of the fact that the individual/single and unique structure in man's biological being is also intellectually and mentally a "single and unique one". The reason for the corruption and communal state of man's "individual and unique" nature in the intellectual domain is that s/he performs the communication with the created ones. On the other hand, in the process during which man makes contact with the Creator as a being who him/herself gained existence out of nothing - in other words, who is the one that is being re-created by gaining an " individual and unique" intellectual existence and his/her created state (existence of creation) is being fulfilled as the "thing 
in itself".

Man's convergence with the "Creator" in the act of creating is the state of his/her witnessing/testifying the process during which the Creator creates Himself through man as "the thing in itself", as the result of which the "created" one is not simply the "word/speech", but the body, mind and life of man having taken shape through his single/individual and unique consciousness. The process in which man is created as "the thing in itself" by the Creator is the phase in which the purpose of creation of man and the realm/kingdoms of existence is revealed to him by the Creator Himself, in his (man's) own creation by the Creator. In this sense, man was created to become "the thing in itself" created by the Creator that He himself is a "thing in itself" . On the other hand, the fact that man has been created as "the thing in itself" means coinciding, in "creation", with the sense of the first moment of creation, and hence, man witnesses his own creation transcending from nothingness to existence and from existence to existence.

Man, within the "word/speech-based (logocentric) universe" which is the single choice- universe pattern where his products bring about "words" and the outcome becomes fictional/speculative, is in a state of being as the one creating nothingness from existence and non-existence from nothingness and annihilating his/her own being/ existence, (Perloff, 1981: 49) whereas in the "major claim-universe pattern", just as in the first creation moment itself, he becomes the "thing in itself" through which the "Creator" Himself is transcended from nothingness to existence and from existence to the plus (+)/positive (active) realm and in which the things s/he produces, the manifestations of creation is himself/herself. Accordingly, man as a created being him/herself within the trinity of "the Creator- creation- created", is the "thing in itself" through whom "creation" becomes an existence by the fact that the Creator creates Himself. On the other hand, the purpose of the fact that he has been created is the "creation" itself which is a "thing in itself".

Man is not a being who has the faculty for / potency to create himself/herself on his/her own, but the one who was created as "the thing in itself" by the creative power of the Creator that He himself is a "thing in itself", which requires for the creator to converge with the "Creator" in response to the greatest question addressed to him in the act of "creation". The answer to the question is the "creation" itself, and man is the "thing in itself " within the act of "creation" manifesting as both the question and the answer to the greatest question. The fact that the answer is the human being himself/herself created as "the thing in itself" is the fact that while being the addressee/respondent of the "greatest question" who has existed as a created being him/herself within the universe of the created, s/he is the human being created to receive from the Creator Himself the answer to the question which makes him/her the "thing in itself". Receiving the answer to the question from the Creator, on the other hand, is, itself, the act of "the Creator creating the human being (man) as 'the thing in itself' ". The "Creator ", in the first act of creation, created man to allow him/her to get the answer to the question of creation from Him (Creator), that is, to "communicate with Him (Creator)", which means converging with Him in the act of creation. In this sense, "man is in the state of an incomplete being who has been unable to fulfill his/her own purpose and reason/cause of existence on earth within the time period when s/he has tried to receive the answer from the communication with other created ones (Derrida, 1981: 52) in other words, during the time s/he has been in relationship with the created.

The spatial existence which is a terrestrial existence where man exists to find the answer to the question is the present state of man who is stuck within the "single choice-pattern of universe" where she/he has been incapable of fulfilling herself/himself as the "thing in itself". The human being, who him/herself is the answer to the trinity of "The Creator-creation-created", and the "major claim-universe pattern", the existence of which, itself, is the re-creation of the spatial existence within the durational existence, emanate through the coincidence of the three basic concepts with one spot, which the man him/herself, and this emanation/composition occurs through the creation of man out of the "time of creation", from out of the universe of the created. Accordingly, "creation" since the beginning of the being/existence has been built upon the coincidence of the three compositions/formations as " the question addressed to the Creator by Himself, the question addressed to man by the Creator and the question to be addressed to man by him/herself.

The Creator is the one with the knowledge of the answer to "the question addressed to Him by Himself" in the act of creation, whose purpose of creation is already the "thing in itself; man, on the other hand, is the human being himself/herself created by the Creator as the one with two-choice /option "trio-structure" who, in his/her freedom, does not know the answer but needs to find it out. With this position of his/hers, the human being (man) is a free individual being who is the addressee/respondent of the "major claim-universe pattern", as the question addressed to him by the creator in the act of creation. Creation is based on the Creator's principle of "equality in non-existence, freedom in existence". Equality in non-existence refers to the fact that the Creator created existence out of nothing. Freedom in existence refers to the fact that the Creator bringing into existence "the universe of the created "including man in His act of creation created man as a free, two-choice (double-optional) system and as a human being capable of (re)producing, while man is a being incapable of creating something out of nothing. Therefore, what disrupts the equality between the Creator and man who matches the Creator in bringing into existence a human being and existence is the fact that the 
Creator creates a being/existence out of nothing; and the option that man is free is the Creator's act of bringing man into existence as a free human being by providing him/her the ability to create. The fact that man cannot be a free human being by choosing one of the two options, that s/he can only create nothingness and non-existence - the fact that those s/he creates wear her/him out - goes to show that as well as being the one incapable of creating existence out of nothing, s/he creates/ produces nothingness-incorporeal realm -and non-existence-death- from his/ her existence by consuming his/her very being created. Creation, for this reason, is a "major claim" and a challenge acted out by the Creator.

\section{The Incomplete of Creation: The Realm of Creation of Man Who is Created as a Half/Incomplete Part of Convergence with the Creator in the Act of "Creation": The Image of the Spatial Existence: " Incompleteness" : The Realm of Existence of Literature: The Horizontal Exit from the Trauma- Creating/Trauma-Based Time : "The Great Fall (Great Descending)".}

Man is the integration of "thought- feeling/emotion- production" as a potential of creation. "The imaging composed of the corporeality of creation at the evolutionary stage of thought into emotion is the consciousness itself that creates the horizontal existence." (Hutcheon, 1980: 57) Becoming corporeal is the process in which the abstraction is made concrete/tangible and transferred into the collective realm/field and anchored there, just like the creative process of a literary work. "Literature is the field existing in the position of man's creative existence found in the horizontality of (Hassan, 1982) "duration" which is the created existence of time within the "spatial existence" on earth and in the "single-choice universe pattern" created by the same existence, and it is the field where the "creative" products which exist on the focus of the integration point of "philosophy-literature-psychology" trio become "voice(d) entities". The literary products that are realms of the "voice(d) entities" are divided into three separate categories as literature, philosophy and psychology, however, on the focus of man's creative potential is the "literary work". In this sense, a literary work is the process of imagining and the images emanating are composed of the knowledge of creating a single literary product by integrating the philosophical knowledge, the field of philosophy; and the knowledge of experience, the field of psychology. The realm where the image portrayal process of the literary work which is the point where man's dilemma of thought and emotion becomes the "product", the emanation of thought -the field of philosophy-, and the processes of thought experiences- (Gür, 2012/1) the field of psychology- are all embodied as voice-entities is the realm of existence of literature(literary realm of existence) and the "focal point" of the potential of creation /creative potential. Therefore, "creation" cannot be solved unless the "image portrayal" process is figured out and a literary work and the human consciousness cannot be solved unless" "creation" is worked out. Hence, literature is the utmost point of image portrayal in which the association of philosophy (as the field of "thing in itself" where the purpose of creation is the creation itself ) with thought and emotion (the field of psychology) creates the process of image portrayal. Within this context, the image portrayal is the formation process of the literary work which is the product unfolding itself at the point where there is a connection between the subconscious/the unconscious -the psychological world of experience- and metaphysics and where the thought experience - the field of philosophy- is linked with metaphysics; thus, the emerging "image" becomes the literary work which is this process itself. Thus, the realm of existence of "literature" necessitates the association of "emotion- thought-product" trio which lie in the position of the field of philosophy and psychology incorporated in the "creation" process itself. Within the "spatial existence", the reason for the horizontality of man, a biological system whose incorporeal being is composed of thought-emotion-product trio/triplet, is the fact that the image portrayal in creation gets in contact with the created time of existence at the moment of thought emergencephilosophical experience. The created time of existence is the utmost/final point that man reaches on the upper limit of thought, which is the place where metaphysics starts. (Gür, 2014/2: 516) Thought, at the time of its birth/emergence merges with the created time of existence-which is the duration- due to the fact that it does not get in contact with a vertical center of existence, and the experience "portrays the images" of the experience of thought at the stage of getting evolved into emotion.

"This is the formation of the "creation " image itself which takes form at the stage of the evolution of thought into emotion." (Bass, 2000: 89) The phase/stage at which thought, from the moment of birth, is evolved into emotion occurs with a speed of thought -the speed of light. The horizontality of the stage of the image formation in the process of "the image portrayal of creation" is the stage at which thought is evolved into emotion, and it becomes the fundamental point determining the relationship between "metaphysics-creation" at the moment of the formation of creation. The relationship in question becomes horizontal because of the fact that thought and emotion do not exist at the upper point in a "vertical center", and this stage of formation also becomes the process itself which creates the "image consciousness" that has also been the consciousness of the productions/creations of man's existence within the spatial existence until today. Portrayal of images is fufilled by the fact that the stage of thought being evolved into emotion within the spatial existence 
has come to an end in the realm of corporeal existence. On the focal point of philosophy-literature-psychology triangle, the formation of the horizontal image portrayal of man's thought-product-emotion integrity/unity, which is the literary field of existence, is the process itself in which man gains consciousness/awareness.

Just as the light cannot return to its source and disappears into the black hole, so does thought return by evolving into emotion but not with the same originality as it emerged/was born at the moment of its emergence/birth; the fact that knowledge becomes personal creates the process of thought experience, it disappears into "duration" that is the field of the subconscious (the unconscious) -metaphysics- and cannot go back to the source. This experience of thought in philosophy is the phase coming to a close through the loss of consciousness -through fictionalization- as the result of thought being unable to become vertical by being engulfed in the "vortex of the collective sub-conscious" at the stage of evolving into emotion. This is because thought, at the stage of formation, does not encounter another 'thing in itself' center as its respondent but meets with the created time itself and shapes, as the utmost boundary of metaphysics, the existence (used- potential, collective past of the created duration) of another realm of existence which transforms the "created" image into word/speech. At this stage of image portrayal, consciousness evolves "its relationship with metaphysics into emotion- experience of thought- which is the field of psychology existing in the position of the subconscious/unconscious field while thought becomes personal." (Mchale; 1982: 88) Yet, the experience occurs through the communication with metaphysics and the communication takes place between the invisible nature of man and invisible entities - the neutrinos -, which are the "created" time and which exist in the correspondent position of the incorporeal realm of existence of man. Creation, the process of the image portrayal of thought-emotion pair, becomes the "word" or "voice(d)-entity" (Derrida, 91: 104) itself that emerges through the relationship with the created ones via such means.

"The horizontal image portrayal" (Mazzaro, 1980: 78) of the "spatial existence" existing in the position of the image portrayal process of the "literary work" which is the reason for the fictionalization process of consciousness and the inability of thought to return to its source delivers a product from the "created-created" dilemma through the integration of man's creative potential with the "created one" via this means, but the product proves to be unoriginal, and while the "voice(d)-entity" turns into a product vocalizing a known past at present, man's creative potential/potential of creation becomes not a "thing in itself", but alterity, (otherness) something in common. On the other hand, while what is experienced in the evolution of thought into emotion with the speed of light/speed of emergence is the engulfment of the present by the past by merging with the "collective memory of humanity" that corresponds to the sum of " the created time which is the accumulated/collected past time", the emerging thought becomes the image of the integration with the realm of the created and their common voice. The image portrayal process in question becomes the integration that is the cause of the horizontality of "logocentric/speech-based universe", a single-exit, the incompleteness through which thought is evolved into emotion and becomes corporeal, and the consciousness of the spatial existence itself, in the way that it will correspond to all the creations existing in the spatial existence. "Such a circumstance itself, as well as being the image of creation of the spatial existence, is also the " earth consciousness" itself which is the reason for the fact that man cannot be defined as a complete realm of existence that is the thing in itself, and it is the time of existence itself where humanity has been imprisoned since the beginning of their creation. (Riceour, 1995:43)

Here, man's creative potential (potential for creation) comes to fruition by his/her union with the created ones from within the created time; and the process of the thought and creation activities - the evolution of thought into emotion-, which are the exchange of neurones, transports to the present the "collective consciousness" in which the answer to the question that returns to man unanswered, without finding its addressee/respondent is continuously sought for in the pastaccumulated time. The reason why man cannot exist as a "thing in itself" unique to him/her and why his/her productions become a "voice(d) entity" is due to the fact that he is unable to define his/her own time and realm of existence because of this collectiveness. In creation, since thought does not converge with the Creator that is the alternative and single "thing in itself" but with the field/realm of the created which is not the thing in itself, and as man cannot be "thing in itself" because s/he integrates with the realm of the created which is not the thing in itself, s/he settles in state of existence creating "nothingness" in the intellectual realm and "absence in the corporeal/physical realm -timeless-spaceless- and fulfilling, under both circumstances, what s/he has and half of himself/herself with the created ones. With this unification and metaphysics, by drawing a semi-circle as the result of such kind of a relationship, thought activity (activity of thinking) that takes place in the realm of creation -incorporeal- becomes the activity of ascribing value on the invisible entities itself, in other words, dignifying trivial neutrinos existing in man's incorporeal location of invisible entities which is his/her invisible realm of existence and the upper limit of metaphysics at the moment of the birth/emergence of thought. At the stage of evolving into emotion, on the other hand, as the consequence of thought being the product of such a unification, the ascribed values- because the invisible entities/beings are "static" intelligence - cannot create. The state of being trivial/worthless is identical to the static intelligence. Thought transforms into the voice, the voice of tradition/convention 
repeating its accumulated past potential, which is the realm of the subconscious evolving into emotion and leading to the personalization of knowledge while experiencing it. On the other hand, in creation, while the products of the incorporeal realm are taking shape by ascribing values to neutrinos that are the realm of existence of the transcendental field and that have no ascribed value, the unifications of the incorporeal realm manifest themselves through the connection of man with the invisible entities existing in the incorporeal location of trivial neutrinos.

The experience materializing in consequence of the imaging/image portrayal "manifesting itself in this way results in the connection between human consciousness and the collective field, which is established by the sub-conscious, and get engulfed in it. "The circumstance "under which the data of this field structure "human consciousness" coincides with uniting in the incorporeal realm with the other people - the incorporeal realm of the other people existing in the incorporeal realm of existence - in the spatial existence of the physical body as the ultimate point of the created thought, and the image, by becoming corporeal, manifests itself through the conveyance of experience to the corporeal realm. "Life", as the result of this consciousness, becomes the experience of the fictional realm materialized in the corporeal/physical one. This cycle of semicircular spatial existence is the traumatic condition itself under which man, within such an existence, produces nothingness from his/her own existence and absence from his/her nothingness, consumes his/her own potential of existence and is brought into connection with the collective field by the word/speech s/he created, since the trauma is the formation stage of the image consciousness itself that is the literary consciousness within this loop. The literary work" corresponding with the schizophrenic time perception or the traumatic life that is the process of the image portrayal itself turns into a zero point at which its contact with the metaphysics create nothingness and becomes, at speed of thought (speed of light), the processing of the accumulated memory perceived in the thought activity existing in the incorporeal realm of existence. At this state, what is created is the trauma created by man after having lost touch with the tangible reality, by perceiving as a whole, at speed of light, the invisible realms of existence and the sum of relationships consisting of the collective incorporeal realm of the other people existing in this realm. However, this traumatic condition becomes the "daydream" itself and the state itself in which man loses his consciousness in the collective memory of the sub-conscious that has taken shape with the sum of relationships from which s/he cannot go back to the previous state. "Daydream" known as the life experience of a "literary work" is the activity itself through which the circumstances never related with each other are brought together in a physical/tangible living environment by the fact that this traumatic condition takes possession of the consciousness, and it is the "great consciousness" partnership with which such kind of perception spreads throughout the whole humanity.

The trauma in question, through medium of "prevalence", exists as the basic element building up the structure of the ultimate human- postmodern subject; thus, the "chaotic" consciousness of the subject is imprisoned within a profound "past", within the timeframe of the great subconscious. "Due to the fact that all the creative activities (creations) of the subject happen with the same consciousness, both his/her intellectual and corporeal/physical being become engulfed within the "image consciousness", and humanity becomes attached to the consciousness that creates the trauma itself owing to the same traumatic consciousness." (Gür, 2014/3: 172) This is the "collective time of existence" of humanity which the ultimate human- postmodern subject also exists in. Man, in this collective time of existence, exists in a state of profound subconscious imprisoned "within the created time"; this profound subconscious personalizes the emerging thought- philosophy- in the image portrayal through the subconscious -psychology- , and hence, the image of creation becomes the horizontality itself in which "humanity incessantly produces/creates the same image" over and over and narrates/transfers (Gür, 2014/4: 45) it through the conveyance of the collective realm to the physical one within the closed loop that is the process of the "collectiveness of the subconscious". Existing in the spatial realm of existence which is the "single-choice universe pattern" and the great image of which is the " big-bang universe pattern", man plays a part in the state of existence which falls within the incomplete (halfway) part of the whole in which the great image of creation cannot fulfill/complete itself and in which the known part of the earthly existence comes to an end through the loss of the physical body, in other words, death which is the only way out (exitway). (Gür, 2014/5) Just as the rest of the black hole cannot be conceived once the journey of light is over when it ends up getting lost within the black hole because it cannot find the way back to its source, so does the horizontal exit refer to the state in which the physical death of man that breaks off the relationship between him/her and the kingdom of existence keeping its cycle apart from him, and the death of his/her thought that is cut off from the incorporeal to become corporeal and die by becoming engulfed within the physical body in the "production activity" s/he performs while still alive exist within the same loop. 


\section{The Primary of Creation: The Creator's Conversation with the Time He Created in the Act of "Creation" : " The Image of the Vertical Existence", " Thing in Itself", 'Voice-entity", "Fulfillment/Completion in Durational Existence, "Heptamerous (sevenfold) Existence"}

"The primary Image of Creation" is the process itself during which the "great image of creation" takes shape in the created time. Image portrayal is the process of the image manifestation opening to human consciousness through the creation of a third/tertiary time of existence in the "vertical image portrayal of the durational existence" of the sum of the time of existences created so far, starting from the time of the primary moment of creation, passing through the first creative moment of the universe of beings and humans until today. "The image portrayal of the vertical existence" is the image manifestation phase and image of creating a complete/fulfilled existence in which man's incorporeal realm integrating with metaphysics where s/he solves the "creation" problem with the Creator Himself takes shape by converging with the Creator that is the "vertical" center of existence. "The primary image of creation" comprises the process during which man,who is made up of the association of a triad structure as "thought-emotion-product", is the "the thing in itself" and establishes a communication with the Creator that is the "the thing in itself" as the result of a creative process consisting of six stages in the act of creation. The vertical image portrayal/ manifestation, which is the image of "durational existence" in the six-stage- creation process, takes man's creative potential status that exists as the association of "thought-emotion-product" in the spatial realm of existence as the starting point of his/her having been created as the "thing in itself". This is the state where the ultimate point of the integration of the potential of existence (emotion-thought-product) of man's creations with metaphysics within the spatial existence is the beginning. The "heptamerous (sevenfold) existence" which is the same as the creation process of the "major claim universe pattern" and which means the resolution of the "great image of creation" has the quality to clarify the three temporal (time) problems. Accordingly, the Creator is Oneness whose own time and realm of existence is independent of those created by Him and who created the universe in six phases and is still in the process of creation.

The creation activity of the Creator that is the "thing in itself" , having met those He created in "the act of creation" once, suggests that man's creation and the creation of the universe were the result of the same process and still continue to be so in the way that it will bring into the open the "creative phases/stages of the vertical existence". (Rorty, 1979: 27) The moment of the rising/emerging of thought in the big-bang universe pattern or the "logocentric/word-based universe pattern" corresponds to the moment of the "big bang". Whereas, the universe keeps on "being created as the created one " through the process of thought emergence, its evolution into emotion and materialization/ manifestation. Accordingly, the universe created out of the integrity of the Creator's emotion-thought-product is the one that drifted away from the time of the Creator as a created realm of existence right from the beginning of creation. Therefore, the "singlechoice condition" within the spatial realm of existence is the overall existence of the universe of the created beings where man also exists and the duration of existence itself. What creates the alternative and places man in the position of a twochoice- triad structure is his/her ability to converge with the "Creator" in the time of creation within the "third/tertiary time", which is the "act of creation itself", as a being composed of the sum of these two different time spans. In this sense, man exists in the spatial realm of existence as a being who has never been to the durational time of existence which is his/her other half belonging to him/her - the other half of his/her own potential of existence. Whereas, the "image of vertical existence" is the fulfillment/completion of man as a full circle of existence by uniting his/her "half image" in the spatial existence with the "image" of the durational existence. This condition of man puts forward that the two-choice structure of man was created as a being who was "the thing in itself" through creating a "third/tertiary time", which suggests that being human means being the "thing in itself". The tertiary (third) time is the modern definition of man that originates from the fact that man, who converges with the proceeding "great image" of the moment of creation, and with the Creator in the "great image of creation " in the durational existence, is created as one complete realm of existence. The "third/tertiary time" unites the existence of man in the spatial existence - horizontal state - with the verticality in the durational realm of existence, and man becomes a "one complete being/existence" who has achieved the purpose of creation that unifies him/her with both his/her corporeal(physical) realm in the spatial realm of existence and his/her incorporeal realm in the durational realm of existence, as well as becoming the one who has fulfilled this purpose together with the Creator. For a human being to become the "thing in itself" is to have his/her incompleteness (half- state) incessantly completed by the "Creator" in the act of "creation".

The "primary image of creation" which exists within the great image of creation is, itself, the purpose of the creation of man that gets clarified by the convergence/union of an with the Creator in the process of his/her being created as one complete being with his/her essence - human- as the "thing in itself", and that which comes to light through the unification with the "great image of creation". The "image of the Essence" (the primal/ Source) is the "great image of creation" itself, which is the process when the three essences/principles emerge, take shape and yield results. One of the 
three principles is the "creation" itself, the second is the "Creator" Himself, and third is man (human being) him/herself. "Creation" is the Essence, the Principle, the potential given to man by the Creator as the "thing in itself", and it is the potential of creating which only exists in the Creator. The focal point of the "image of the Essence" which joins the "Creator" that is in contact with man in this potential directly with him/her is the "pulse". While the pulse is beating with the rhythm of the time of the created beings in the semi-existence within the spatial realm of existence, the Pulse that beats with the time created through the convergence of two existences which is "one complete realm of existence" throbs together with the "Creator" by uniting with "the creation time of the Creator". This situation in which man becomes the Pulse throbbing with 'Himself' by uniting with the Creator's Pulse, both physically and mentally - as body and spirit - , is the "primary (essential) image of creation" in which two principles/essences "converge in creation" in the third principle as the "thing in itself". The "primary/essential image of the Creator" which exists within the great image of creation, the primary/essential image of man and the primary/essential image of creation represent the new beginning stage of human existence, since man was created to resolve this image. Accordingly, the universe of the created, including man, which exists with the kingdom of beings in the created potential duration; the universe in which the kingdom of beings are created from within the continuum of this process in the spatial existence and that which consists of a closed loop by constantly carrying on from non-existence to existence and from existence to nothingness has completed its duration of existence.

The duration in question is the overall potential of existence which comprises the continuum of the image portrayal/manifestation of thought having taken shape after emerging and evolving into emotion. Within the created time, transition from non-existence to existence is the same as the process of transition from the invisible to visible, from the non-physical to physical and from time to space. The fact that thought returns to the corporeal/physical field it once emerged from by being incapable of getting out of the overall created process of existence before death, and the loss of light within the black hole become the same as the death phenomenon. In death, the physical body comes to an end in the "spatial existence" where it has existed, and the incorporeal realm, which is the potential of existence, exists no more. The non-existence of the "incorporeal realm" which is the same as thought ending in the physical realm while still living suggests that man's physical body is not in company with his/her soul while living in this realm. The incorporeal realm is the same thing as the potential of existence/being which exists in man in the "spatial existence", and on the other hand, the process which shapes man's "creative potential" is the "creation" activity itself, during which man allows the trivial, worthless neutrinos 'to gain existence' by ascribing value to them. Thus, the material cycle which does not exist out of nothing and does not perish in existence is the cycle of the physical body. The realm at issue is the personalization of the closed loop of thought evolving into emotion through experience in which the spirit itself - the incorporeal- living in the spiritual realm of existence does not exist but in which the manifestations are interpreted as psyche or spirit. This creates a closed loop, and the activity of thinking which integrates with the past in the subconscious therapies transforms into a form of ascribing/attributing values to the "incorporeal realm itself that gets involved in the expended (used) duration". Such a condition is the closed loop/cycle of the spatial existence itself where humanity flows from existence to nonexistence, from the present through the past through medium of the "accumulative/collective memory" - the great collective subconscious - that is united with in the act of making search. The fact that the act of creating that takes place in the incorporeal realm occurs in this way is the reason for man's being destined for nothingness from out of existence and non-existence from out of nothingness due to the fact that the personal subconscious takes shape with the time of the collective subconscious (integration ) by man's being unable to have a time of creation and existence peculiar to him/her despite the single and unique biological mechanism s/he possesses.

The spirit - the incorporeal - is a potential of existence that gains its existence through the completion/fulfillment of man by the Creator in their convergence, in other words, it is the potential of existence that subsists in the durational existence descending to the spatial realm of existence which is the realm of the corporeal. In this sense, the process of creation that takes place through the vertical contact with the "thing in itself" is the unity of man's spirit with his/her physical being, which is the vertical existence through which man whose physical being is united with his/her spirit, "the thing in itself" is in direct communication with the Creator; and it is the very form of man himself/herself in the very beginning. The original principle of creation of a being and the purpose of the creation of man coincides with the Creator's purpose of creating man, and the purpose of creation becomes the resolution in which man fufills the act of "creating" itself within " himself/herself". Therefore, literature which is the field of a "thing for itself" -the realm of the image constitutes the evolution stage of thought into emotion on the boundary of the ultimate point that knowledge reached in the "time of history" and the relationship between metaphysics and philosophy - the field of thought-, and by transforming itself -reaching- into the realm of the subconscious, which exists in the field of psychology, and falling within its boundary, it becomes the state in which "experience and metaphysics" integrate. The field which is the emotionthought integrity and which informationally exists in the "focal point" of the relationship of philosophy-metaphysics and 
psychology-metaphysics finds its place in the position of man's potential of creation being manifested as the "thing in itself" in a vertical center. In this sense, the field of literature - as being the activity of the formation and tangible manifestation of thought and emotion, and as the realm of "image portrayal" and as the "horizontal image manifestation" in a triad closed loop in the spatial existence as well as being the consciousness of a single alternative - is the field where the "thing in itself" dissipates. In the vertical image portrayal/manifestation in the completion process of the "durational existence", fictionality gives way to the creation of man as the "thing in itself", and creation becomes the purpose of creation itself by means of which man himself/herself is created as a form, a consciousness. In this sense, the durational existence becomes the completion of man, who is composed of a biological structure with a triad creation activity on earth, with the "trinity/triad" of the creation activity of the Creator that is the sole "thing in itself".

Completion is the process during which the activity of the original/primary creation to be able to exist with the Creator in the sense/meaning of creation is open to the testimony of man in the mental and physical realms, and it is the tangible reality which means understanding the informational and vital foundations of tangible realizations and experiencing them; thus, it is the process of "the creation of the self". It is also the fact that man exists mentally as "the thing in itself" and becomes the creation process of the exposed information himself, and that the uniqueness in physical body and information that is the mental realm activity are unique to the individual created as the "thing in itself". It is the acitivity through which man, as the "thing in itself" is completed/fulfilled by the Creator, and it is the coincidence of the mental-incorporeal(spiritual) realm (formed of thought-emotion-product) with the trinity/triad of thought-emotion-product that exist in the Creator's purpose of creation.

The image portrayal/manifestation process of the vertical existence is the convergence/unification of thought, at the moment of emergence/birth, with the Creator that He, himself is the "thing in itself" before it (thought) descends on earth/becomes materialized; on the other hand, the convergence of thought with the Creator is the convergence of man, who is in the spatial realm of existence, with the trinity/triad of the three time spans, "the Creator-creation- created", in a "vertical thought". First by having raised the great question, which is unique to man, to the Creator, from the ultimate point of the spatial realm of existence, the emergence of thought takes shape at that same stage during the process in which the form of the answer received from the Creator is evolved into emotion. The thought in question is the "vertical image portrayal/manifestation" that is unrequited (remains uncovered) in the horizontal existence which is the spatial realm; that which can only be worked out together with the Creator and the thing through which "creation " shapes life only when the question and the answer are received from the Creator. Thus, the image manifestation process is the realm of existence itself that is created through receiving the answer from the addressee/respondent to whom the question is raised, and it occurs by starting to take shape at the stage of the emergence of thought in man, evolving into emotion in the horizontal plane and then getting completed by becoming materialized in its descending to the corporeal realm.

The image portrayal/manifestation in the horizontal plane occurs in the form of personalization of thought at the stage of evolving into emotion and transformation of the personalized sense/meaning into the material/tangible experience in the corporeal realm. However, thought becomes something common or collective in the horizontal image portrayal owing to the fact that it does not converge with the "thing in itself", and man experiences the "thought emerged from himself/herself" not as the activity of a genuine creation and understanding because of the integrations in the collective realm, but in the form of conveying fictionality to the corporeal realm. In the horizontal plane, the relationship of philosophy-literature-psychology with metaphysics always and still occurs through this loop. In the image portrayal of thought-emotion-product triad in a vertical plane with the "Creator" as the alternative existence in the spatial realm of existence, thought converges with the Creator and the Creator's creation activity at the moment of emergence; the convergence speed of thought occurs at speed of light/speed of thought; yet, the its process of materialization through evolving into emotion takes place as in the difference that occurs among the time of the creation of universe and the time of creation and the time of the created beings. This is the phase during which all these creations happen at speed of light/thought but the shaping-up process descends to the time of manifestation in the time of corporeal/physical perception.

The re-creation of man by the Creator as the "thing in itself" continues to occur as the "equality in non-existence, freedom in existence" principle, which refers to the primary/original principle of creation. Accordingly; man, who exists in the created spatial realm of existence a created being and establishes communication through his/her relationship with the created physical and non-physical things - time and space- , and who was created from out of the creation time of the Creator- "time not yet created"- as the "thing in itself" in the act of creation by drifting away from the realm of the created ones in the durational exsitence that is the vertical existence is the one whose activities of creation coincides with the Creator's act of creation. In this context, the phenomenon that needs to be resolved is the Creator's act of creation itself that carries on like the first creation, because the fact that man was created in the durational existence suggests that s/he 
was created to complete him/herself purely by working out the act of creation and the Creator in "creation" , as an incomplete being within the spatial existence.

At this point, the vertical image portrayal/image manifestation which needs to be resolved and in which the Act of Creation that is lost in the corporeal field in the spatial existence and ends with the process of collectiveness creates a different outcome in order to become the same as the image portrayal of "Creation" exists in the focal point of man being created as a two-choice system/structure. Accordingly, creation corresponds to exactly the half of having been created in the form of the spatialization of time, that is, as the process of creating space- tangibility- from out of spaceless time. The halfness/incompleteness corresponding to the descending stage in the formation of creation is the process itself in which thought emerges and takes shape on earth, transforming into a tangible image. Creation(being created) and the process of existing on earth, the common image of which is the "Great Fall", indeed corresponds to the half of the "great image of creation" and man, therefore, has descended to the spatial realm of existence in order to complete his/her other half. The durational existence, in this sense, is the return of this half from the corporeal realm to the Source where thought emerged by converging with a vertical " center of existence " - the Creator, the thing in itself-, which means the process of being created by converging/uniting with the Source.

In this sense, the thought that becomes corporeal and dissipates in the halfness/incompleteness of the spatial existence turns out to be the genuine creation activity through which man completes his/her half and reaches both mental and physical integrity by evolving from the corporeal body, once again, back to emotion and thought through the medium of a vertical imaging/image portrayal. This condition is also the reason/ ground for the creation of man as a complete being with a single body and spirit of his/her own by the sole and unique Creator existing as the seventh element in the sixfold creation activity. The heptamerous existence forming the "Principal Image of Creation" is the image portrayal of the descending experience through which thought, at the time of emergence, converges with the "Creator", evolves into emotion without being corrupted at the stage of transforming into emotion, in other words, it is the image of the experience through which man,by means of thought experience, creates his/her own unique/authentic life story -which is his/her own realm of existence- the " personal story" that does not coincide with the created beings.

Ascension is the third/tertiary time-experience of the essential and functional realm of man, who was created as the "thing in itself" at the stage of descending, and his/her convergence with the Source s/he was born of, the moment of being the "Creator-creation-created", without ever losing her/his haecceity/originality. While the descending stage is the stage when the Creator descends on earth in company with thought-emotion-product association, the ascension stage ends with the convergence with the Source through the evolution/transformation stage of body into emotion and emotion into thought. However, this ending, meaning "completion", is the new alternative existence where the Essence of man and the Essence of the Creator meet/converge with each other in the "Essence of creation" where the original/primary emergence point that started with descending now meets with the ultimate point that is reached through ascension. "The great image of creation" is formed of a heptamerous structure/constitution, and six of this heptamerous constitution are composed of the "created time of existence" and "the kingdoms of existence created within the same time span", which manifested through the relationship of the Creator with those He created in the act of creation. The created kingdom of existence is finite, and the time of existence/beings consists of the overall duration of existence determined at the moment of creation. The time mechanism and its functioning and the diversities in time coincide with the process of the emergence speed of thought and its evolution into emotion and then transformation into a product. The speed of thought which is close to sound and light/flash but which is pretty much faster than them exists in two distinct time spans which distinguishes the emergence moment of thought -the speed that occurs with the Word "Be! " - that is, the time of the creation time, with the time of the realm of the created, but which exists as in the difference between the speed of thought and the physical body of man or between the speed of light and the speed of the physical body. Accordingly, " the created universe of existence and the determined duration of the created time " exists within the Creator's formation/manifestation process of His creative activity in the vertical existence, and the universe is proceeding towards the sundown(sunset) of that great Day within a single big Day, which is the Creator's time of existence. The time of the created kingdom/universe of existence exists within the great time of one single Day, which is the Creator's time of creation.

According to this, the universe was created in six days in six phases, and man exists in the position of existence where s/he is supposed to complete/fulfill the six phases. Therefore, the created time, "within the duration", is being created by the Creator through continuously ascribing values to trivial neutrinos, - creating the time of existence from within-, and in such creation, no existence from non-existence and vice versa occurs. In other words, the universe neither grows nor lessens; nevertheless, as the result of the operation (utilization) of the designated time - lessening from withinthrough the utilization of its own duration - the end of the cycle has approached, since the duration is the potential of the designated time itself, which is the created time. In this type of creation, the Creator, just like He did in the primary 
moment of creation, intervenes in the created kingdom/universe of existence from within - the - void spaces - and the created time continues being created through the completion of "one". However, what is primarily important is that the created time of existence in which humanity also exists is now within that "Great Day" of the Creator's first, primary creation. Accordingly, "the overall duration of the universe of the created" corresponds to the sunset/evening of one day of the time of creation, which means it consists of "one single day on which the morning is about to touch the evening/sunset of that same day." Of the two realms of existence; " the duration of the created realm of existence" exists within this "created Great Day", and in creation, the process of " the evolution of thought into emotion and materialization " exists in order to be completed/fulfilled. In this sense, "the great image of creation" is built upon that single Great Day. Humanity, in the created time of existence and with the ever- recurring daily cycle, is living and experiencing their evening -sunset- time, which is the time to meet /converge with the Creator - dawn - in the sense/meaning of creation and the time to complete/fulfill that meaning. The sundown/sunset determined for the kingdom/universe of existence is the completion process during which the meaning of "creation" created at dawn on one single Great Day will be revealed in one single great Evening, which will be the completion process of its duration of existence. The dawn and the sunset hours repeating each morning and evening twice in the created kingdom/universe of existence represent two meaningful aspects: The former is to meet the Creator in the primary meaning(sense), which is the "meaning of creation"; the latter is the completion of the meaning born in the morning, heading towards the evening to fufill its course.

This dawn and sunset hours of one single Great Day are the manifestations of the "great image of creation" in the created time of existence, yet, they are the coincidence (overlapping) moments of the great image of creation from within its own time. Accordingly, time of creation is the six-phase completion of one single Great Day in the "universe of the created", and it is also the time of the spatial realm of existence in which half of the completion corresponds to the descending process. The spatial existence is the descending stage itself that is about to be completed by the history of humanity. - Evening is about to fall in the interval between the morning and the evening.- Ascension, which will take place when evening falls, is the fulfillment of creation itself for which humanity, who will be converging with the Creator in the meaning and purpose of creation, will complete the cycle by passing through the spatial realm of existence towards the durational realm; in other words, it is the fulfillment itself that will start with the completion of the provided period of time within the spatial existence. It is the transition period of humanity; humanity who has been living in the life span given to him/her for a determined period of time for the kingdom/universe of existence in the spatial realm and who has been sustaining his/her existence by ascribing value to neutrinos within the provided potential of period, as in the act of creation itself, is now experiencing a transition from the perception of a "single-choice "universe to the universal perception of the second option/choice. Humanity who has not once met or encountered the Creator during the period provided for them within the act of creation itself or who failed to be the "thing in itself" in realizing the communication that was the purpose of creation will have transcended to the durational existence in the sunset of his half (incomplete)existence - apocalypse/resurrection-which is the completion process. This is the compulsory encounter humanity has failed to realize, that takes shape in the end of time, as determined by the durational existence. The creation process currently continuing in the "Great image of the Creator" is the "miraculous" time that has not yet been created, the non-existent time, the time when the Creator and man converge / unite in creation, that which is created from outside of (beyond) the created time and that which enables man's realm of existence to be identified as a free being.

Man, who converges with the Creator in "creation" within the miraculous time, leaps out of the "created time of existence" and joins the "duration", whereas he is the human being who exists in the realm of the created with his/her physical body that is his/her only corporeal realm of existence that was created for descending to the material world. As the "thing in itself" and while existing in the "tertiary/third period of time ", man's exists within the created time to experience the occurrences "within his/her own created circle of existence" and to testify/witness the events / incidents " in the realm of the created beings within the created period of time". Creation, on the other hand, is the image portrayal/manifestation of the process in which the images emanating through the convergence with the "Creator" at the moment of thought emergence in the Creator's time of creation are realized with the existence of the Creator, which is the stage of image evolving into emotion - emotional and personal realm -, and it is the image process which is born of man but as it reaches its Source by coinciding with the Creator in creation, it is the image manifestation of the process in which man is created as a genuine "thing in itself". This is the free realm of existence itself where the "tangible and real act of creation" creates it as the "thing in itself" and produces tangible mental or intellectual products in the corporeal realm (the mental and physical realm of the individual created as the thing in itself in image manifestation) where descending on earth takes shape by creating a genuine life story of the being. The coincidence of the creation activity with the time of the Creator creates a center of the "thing in itself" as "knowledge and awareness of creation", which becomes the purpose and meaning of man's creation itself in the primary and the continuous creation process. Thought, from the very beginning of its birth/emergence, can be followed-up without dissipating until the moment of evolving into emotion and 
becoming materialized/tangible, and the genuine "thing in itself" created by man becomes the spontaneity that is the "thing in itself" story of man's existence on earth, which is produced from his/her "mental and emotional" foundations. In this sense, the fictional consciousness of "the horizontal image of the spatial existence", which is the image portrayal/manifestation of the realm of voice(d) -entities consisting of the philosophy-literature-psychology triad/trio in the horizontal existence-, and the literary realm of existence start to change, as well.

This new realm of existence totally changes the creation-metaphysics relationship in which literature experiences the fictionality of words, philosophy deals with the speculative accumulated questions and psychology experiences the "vast cumulative collective memory". In the new existence and state, the "literary realm of existence" becomes the tangible, genuine realm of existence of the process in which thought and emotion are manifested in a unique way and in which man completes/fulfills him/herself with the Creator as the thing in itself and creates his existence over again. This is the purpose of the creation of man and the story of man's completion through which man does not produce fiction but what is genuine and through which he testifies his own creation. Human consciousness escapes the the process of nonexistence that occurs by having his/her thoughts and emotions used by the "created collective realm of existence" which causes thought to die or dissipate - lose its originality- while evolving into emotion; and awareness reaches a verticality where it can monitor/ follow-up the time of the subconscious, tha is, the whole spatial existence. The subconscious now avoids being the result and the connection of the "collective subconscious" which is already expended and expired; it does not allow anymore to be the pit (hole) of existence ( falling into the center, nothingness, getting lost in the time of the subconscious) and memory where human consciousness dies and knowledge turns into something common and collective by personalization. On account of the fact that the meaning itself that is created in "the image portrayal/manifestation process" of the durational existence and the product that is produced are the tangible information and experiences of such existence, the fictional consciousness emerging in the horizontal existence in the field of literature is the consciousness of the "thing in itself"-center. The "image consciousness" which emerges in the form of the process of experiencing the fictional realm is the experience of the "thing in itself" within its own concrete/real life in which experience is created and which, itself, is the "experience of the image". The miraculous time is the time of the " principal/essential image" of creation in which man resolves the issue of creation as the "the thing in itself" and completes and fulfills him/herself as a free individual being. This state is the time of now itself in which "humanity's history of existence exists at the zero point of the spatial existence, at the stage of humanity's transition from the spatial realm to the durational realm of existence". (Gür, 2014/2:254)

\section{References}

Altieri, Charles, "The Postmodernism of David Antin's Tuning" College English, 48:1, 1986, p.19

Bass, Alan, Difference and Disavowal The Travma of Eros, Standford University Press, Standford-California, 2000

Brian Mchale, "Modernist Reading- Postmodernist Tex: The Case of 'Gravity's Rainbow', Poetics Today, 1:1-2, (1982), p. 88

Derrida Jacques, Dissemination, translated with an Introduction and Additional Notes by Barbara Johnson, The Athlone Press London, 1981

Derrida, Jacques, Acts of Literatüre, copyright 19922 by Derek Attridge, New York U.S.A, 1991 p.801.

Derrida, Jacques, Margins of Philosophy, Translated with the Additional Notes by Alan Bass, The University of Chicago Press, Chicago U.S.A, 1982

Derrida, Jacques, The Animal That Therfore I Am, Translated by David Wills, Fordham University Press, New York U.S.A. 2008

Gür, İmran, 2012/1 The Diary of İmage (İmgenin Günlüğü) Alternative Existence: Spatial Existence, The Criticism of Durational Existence, Publisher: Cinius, İstanbul, Turkey, July-2012, s256p.

Gür, İmran, 2012/2, "The End Of The Postmodern Subject The New Human Alternative Existence, The Consciousness of Revalation, Sense it Self, God Particle", Itobiad, Journal of the Human and Social Science Researches, 2012 | Cilt.1, Sayı: 4 - Volume.1, Issue: 4, p.98-131, Ankara/TURKEY

Gür, İmran, 2013/1, "The, Volition Ethics As The Alternative of The Matchless: The Voluntary Human As The Own Purpose Of Creation", The Journal of History School Volume: 7/XVI, 2013, p.34-56, Izmir/TURKEY.

Gür, İmran 2014/1, "The Principles of Postmodern Subject: Settlement With the History of Humanity", The Journal of History School Volume: 7/XVII, 2014, p.19-44, İzmir/TURKEY.

Gür, İmran, 2014/2, "Humanity Lost In The Fiction it It Created: PROBLEM M, Beginning of Alternative Existence of Alternative Human: Theorem A: A Hole In Time: From Purgotory to Apolocalypse" "Meditarrenean Journal of Social Sciences, Volume 5, No: 3, March 2014, p.515-523, Rome/ltaly

Gür, İmran, 2014/3, Exit from the Purgatory, Akçağ Publishing Company, Ankara, 2014.

Gür, İmran, 2014/4, Transition from the Logocentric Universe to The Big Claim Universe Model. M PROBLEM, THEOREM A, Akçağ Publishing Company, Ankara, 2014.

Gür,, İmran, 2014/5, Evolving from the Arena of Infinity: The Sırat, Akçağ Publishing Company, Ankara, 2014. 
Hassan, İhad, Hassan, "The Dismemberment of Orfeus: Toward a Postmodern Literatüre", Newyork, Oxford Universitiy Press, 1982, s.162

Heidegger, Martin, Being And Time, Translated by Joan Stambaugh, State University of New York Press, Albany-U.S.A. 1996.

Heidegger, Martin, Poetry, Language, Translated and İntroduction by Albert Hofstadter, Thought, Harperperennial Modernclassic Press, New York, U.S.A, 2001

Hutcheon, Linda, Narsistıc Narrative: The Metafictional Paradox, (Waterloo, Ont., Wilfred Laurier University Press, 1980, s.179

Kant, İmmanuel, Graunding For The metaphysics of Morals Third Edition, Translated by, James W. Ellington, Hackett Publıshing Company İNC., Cambridge, 1993.

Mazzaro, Jerome, Postmodern American Poetry, Urbana, University of Illinois Press 1980, p. 78

Nietzche, Friedrich, The Birth of Tragedy Out of the Spirit of Music, Translated by lan Johnston Vancouver Island University, Nanaimo, British Columbia Canada, 2009

Perloff, Marjorie, The Poetıcs of İndeterminacy: Rimbaud to Cage, Princeton NJ, Princeton Unıversity Press, 1981, p. 49

Wilde, Alan, Horizon of Assent: Modernizm, Postmodernizm and the İronic İmagination Baltimore and London, Johns Hopkins University Press, 1981, p. 96 